\title{
Association of physical activity with blood pressure and blood glucose among Malaysian adults: a population-based study

Chien Huey Teh ${ }^{1 *}$, Ying Ying Chan², Kuang Hock Lim², Chee Cheong Kee ${ }^{1}$, Kuang Kuay Lim², Pei Sien Yeo², Omar Azahadi ${ }^{2}$, Yusoff Fadhli ${ }^{2}$, Aris Tahir ${ }^{2}$, Han Lim Lee ${ }^{1}$ and Wasi Ahmad Nazni ${ }^{1}$

\begin{abstract}
Background: The health-enhancing benefits of physical activity (PA) on hypertension and diabetes have been well documented for decades. This study aimed to determine the association of PA with systolic and diastolic blood pressure as well as blood glucose in the Malaysian adult population.

Methods: Data were extracted from the 2011 National Health and Morbidity Survey (NHMS), a nationally representative, cross-sectional study. A two-stage stratified sampling method was used to select a representative sample of 18,231 Malaysian adults aged 18 years and above. The PA levels of the respondents were categorised as low, moderate or high according to the International Physical Activity Questionnaire (IPAQ)-short form. Blood pressure and fasting blood glucose levels were measured using a digital blood pressure-measuring device and finger-prick test, respectively.

Results: Systolic blood pressure (SBP) level was positively associated with PA level $(p=0.02)$ whilst no significant association was noted between PA level and diastolic blood pressure (DBP). In contrast, respondents with low (adjusted coefficient $=0.17$ ) or moderate (adjusted coefficient $=0.03$ ) level of PA had significantly higher blood glucose level as compared to those who were highly active $(p=0.04)$.

Conclusions: A significant negative association was observed between PA level and blood glucose only. Future studies should employ an objective measurement in estimating PA level in order to elucidate the actual relationship between PA, hypertension and diabetes for the development of effective interventions to combat the increasing burden of premature-mortality and cardiovascular disease-related morbidity in Malaysia.
\end{abstract}

Keywords: Hypertension, Diabetes, Malaysia, NHMS, Physical activity

\section{Background}

Hypertension and diabetes are major and common risk factors for cardiovascular disease. Cardiovascular diseases (CVDs) account for approximately one third of deaths worldwide, with high blood pressure being the leading cause of cardiovascular death in the South East Asia Region. Together with a number of lifestyle risk factors (alcohol use, tobacco use, high body mass index (BMI), high cholesterol, low fruit and vegetable intake and physical activity), high blood pressure and high

\footnotetext{
* Correspondence: chienhuey@imr.gov.my

${ }^{1}$ Institute for Medical Research, Ministry of Health Malaysia, Jalan Pahang, Kuala Lumpur 50588, Malaysia

Full list of author information is available at the end of the article
}

blood glucose account for $61 \%$ of cardiovascular deaths and more than $75 \%$ of deaths from ischaemic and hypertensive heart disease globally [1].

In Malaysia, the prevalence of hypertension among adults aged 18 years and above has been persistent at $32.2 \%$ in 2006 [2] and $32.7 \%$ in 2011 [3], whereas the prevalence of diabetes has been increasing steadily from $11.6 \%$ in 2006 [2] to $15.2 \%$ in 2011 [3]. The high prevalence of hypertension and diabetes are anticipated to cause an epidemic of cardiovascular disease. The Malaysian Second Burden of Disease and Injury Study (BOD) in 2012 reported that ischaemic heart disease was the top killer and ranked first in the top 10 causes of premature mortality (Years of Life Lost, YLLs) and 
top 10 based on burden of disease (Disability Adjusted Life Years, DALYs) [4]. Therefore, the implementation of intensive targeted strategies based on scientific evidence to prevent and control these conditions is of paramount importance.

For decades, a plethora of epidemiological studies have demonstrably proven the metabolic and cardiovascular benefits of physical activity (PA), either alone or in conjunction with dietary changes in reducing the risk of hypertension and diabetes [5-7]. Findings from prospective studies $[8,9]$ and meta-analysis of randomised controlled trials (RCTs) $[10,11]$ indicated that regular moderate-intensity activity and resistance exercise lowered the blood pressure in both normotensive and hypertensive individuals. Similarly, studies [7, 12, 13] also demonstrated that moderate- and high-intensity PA conferred evident health benefits amongst both non-diabetic and diabetic populations by improving insulin sensitivity and glycaemic control. A RCT reported that the incidence of diabetes among high-risk individuals was reduced by $40-60 \%$ through proper diet control and programmed PA over 3 to 4 years [13].

Nonetheless, despite established evidence of the beneficial relationship between PA, hypertension and diabetes, there is a lack of national data reporting on the association of PA with systolic and diastolic blood pressure as well as blood glucose level among the Malaysian population. Therefore, in the present study, we aimed to determine these associations by analysing data obtained from the National Health and Morbidity Survey (NHMS) 2011 among Malaysian adults aged 18 years and above, while adjusted for other potential confounders. Findings from this study could provide evidence-based information to assist policy-making decisions pertaining to primary prevention and treatment of hypertension and diabetes, as well as interventional strategies.

\section{Methods}

Study sample

Data were extracted from a cross-sectional multi-ethnic population-based study, the 2011 NHMS, which was conducted from April to July 2011, across 13 states (Penang, Perlis, Kedah, Perak, Selangor, Negeri Sembilan, Melaka, Johor, Kelantan, Terengganu, Pahang, Sabah, Sarawak) and 2 Federal Territories (Kuala Lumpur and Putrajaya) in Malaysia. Samples were selected using a two-stage stratified sampling method, by which the first stage stratification was performed by states and the second stage stratification was performed by urban/rural localities. The urban area is defined as a gazetted administrative area (a carefully mapped area with definite boundaries which had been notified in the government gazette for public information) with adjoining built-up areas of more than
10,000 people while a gazetted administrative area of less than 10,000 people is defined as a rural area. The Malaysian Department of Statistics (DOS) provided the Primary Sampling Units (PSUs) or Enumeration Blocks (EBs) for first stage sampling and Secondary Sampling Units (SSUs) or Living Quarters (LQs) for second stage sampling according to the 2010 census.

A total of 794 EBs (484 urban and 310 rural EBs) were systematically selected from all EBs in Malaysia via a probability-proportional-to-size sampling technique. Subsequently, 12 Living Quarters (LQs) or Secondary Sampling Units (SSUs) were randomly selected from each EB. Finally, all households and eligible household members within the selected LQs were included in the sample. Details of the sampling method and calculation of sample size have been described elsewhere [14]. For the present study, a total of 18,231 eligible respondents (aged 18-yearold and above) were recruited in the study and written consent for participation was obtained before they were interviewed. The study protocol was approved by the Medical Review and Ethics Committee (MREC), Ministry of Health Malaysia.

\section{Data collection}

The data collection was conducted from April 2011 to July 2011 by trained interviewers via face-to-face interviews using a standardised questionnaire; whilst clinical assessment, which included measurement of blood pressure and blood glucose level, was performed by trained staff nurses. To ensure a higher response rate, only selected respondents who were not at home after at least 3 attempted visits were excluded from the survey.

\section{Physical activity}

The International Physical Activity Questionnaire-short form (IPAQ-SF) estimates the overall PA level of an individual in MET-minutes/week by determining the duration (in minutes) and number of days (in one week) of engagement in three specific types of activity (walking, moderate-intensity and high-intensity activities) across a comprehensive set of domains (leisure time, workrelated and transport-related physical activities, domestic and gardening activities) in the past seven days. MET or metabolic equivalent is a unit that is used to estimate the amount of oxygen used by the body during physical activity. A MET-minutes/week is computed by multiplying the MET score of an activity (3.3 for walking, 4.0 for moderate-intensity and 8.0 for vigorousintensity) by the minutes and days (or sessions) of engagement. Respondents were classified into three levels of PA as low, moderate or high according to the cutoff of total MET-minutes/week in each category [15] as follow: 
Category 1 Low

Individuals who do not meet the criteria for Category 2 (moderately active) and 3 (highly active) were considered to have a 'low' PA level or were physically inactive.

\section{Category 2 Moderate}

a) 3 or more days of vigorous-intensity activity of at least 20 min per day, or

b) 5 or more days of moderate-intensity activity and/or walking of at least $30 \mathrm{~min}$ per day, or

c) 5 or more days of any combination of walking, moderate- or vigorous-intensity activities achieving a minimum total PA of at least $600 \mathrm{MET}$-minutes/week

\section{Category 3 High}

a) vigorous-intensity activity on at least 3 days achieving a minimum total PA of at least 1500 MET-minutes/week, or

b) 7 or more days of any combination of walking, moderate- or vigorous-intensity activities achieving a minimum total PA of at least 3000 MET-minutes/ week.

\section{Hypertension}

Blood pressure level was measured twice in an interval of $10 \mathrm{~min}$ by a trained nurse using a calibrated digital blood pressure-measuring device, OMRON HEM-907. This device was evaluated for compliance to both the American Association for the Advancement Medical Instrumentation (AAMI) and British Hypertension Society (BHS) protocols for accuracy for a non-invasive blood pressure-monitoring device using single observer readings [16]. Both known hypertension and undiagnosed hypertension constituted the overall prevalence of hypertension. "Known hypertension" is defined as self-report of being told they have hypertension by a doctor or medical assistant; "undiagnosed hypertension" is defined as self-perceived as non-hypertensive and had a SBP of $140 \mathrm{mmHg}$ or more and/or DBP of $90 \mathrm{mmHg}$ or more [17].

\section{Diabetes}

Respondents were asked to fast for at least $6 \mathrm{~h}$ for the measurement of fasting blood glucose level using a validated CardioChek PA Analyser [18] via finger-prick test by trained nurses. Respondents with known diabetes or undiagnosed diabetes constituted the overall prevalence of diabetes. "Known diabetes" is defined as self-report of being told they have diabetes by a doctor or medical assistant; a respondent was classified as having 'undiagnosed diabetes' when the respondent was not known to have diabetes and had a fasting capillary blood glucose (FBG) of $6.1 \mathrm{mmol} / \mathrm{L}$ or more or non-fasting blood glucose of more than $11.1 \mathrm{mmol} / \mathrm{L}$ [19].

\section{Anthropometric measurements and obesity}

SECA bodymeter 206 (SECA, Germany) and TANITA318 digital weighing scale (TANITA, Japan) were used to measure the height and weight of respondents to the nearest $0.1 \mathrm{~cm}$ and $0.1 \mathrm{~kg}$, respectively. Anthropometric measurements were taken twice and the average values were used for data analysis. Body mass index (BMI, weight/height ${ }^{2}$ in $\mathrm{kg} / \mathrm{m}^{2}$ ) was used to classify respondents into underweight, normal, overweight and obese based on the cut-off points recommended by the World Health Organization (WHO) [20].

\section{Smoking}

Respondents were classified as non-smokers if they answered "No" to the question "Have you ever smoked shisha, cigarettes, cigars and pipes?"; whilst respondents who answered "Yes" to both questions "Have you ever smoked shisha, cigarettes, cigars and pipes?" and "Do you currently smoke?" were classified as smokers.

\section{Data analysis}

SPSS version 19.0 with add-on complex sample analysis was used to analyse the data after the adjustment for stratification using post-stratified weights. Descriptive statistics were used to illustrate the characteristics of the study population by PA level (low, moderate or high) and socio-demographic variables (gender, locality, age, ethnicity, educational level, household monthly income, employment and marital status). Multivariable linear regression (MLR) or ordinary least square was performed to elucidate the associations of PA levels with SBP, DBP and blood glucose while controlling for gender, locality, age, ethnicity, educational level, household monthly income, employment and marital status, body mass index status and smoking status. Missing data were excluded from analyses and it was ignorable since the NHMS 2011 had taken a $20 \%$ non-response rate into consideration at the sample size calculation stage. All statistical tests were conducted at a $95 \%$ confidence interval (CI).

\section{Results}

Of the 18,231 eligible respondents aged 18 years and above, 99.1, 99.3 and $97.5 \%$ of them responded to the PA, hypertension and diabetes modules of the questionnaire, respectively. The mean age (SD) of the respondents was 42.0 (16.0) years. The characteristics of respondents are provided in Table 1 . The population was almost equally composed of men (51.1\%) and women (48.9\%). A large portion of respondents were urban dwellers (73.1\%). Almost half of the Malaysian population was constituted by the Malays, followed by the Chinese (25.4\%), other ethnic groups (Serani, Iban, Kadazan, Dusun, Bidayuh, Melanau and Bumiputras from the State of Sabah and Sarawak, as well as the aborigines, $17.8 \%$ ) and Indians (7.0 \%). Most 
Table 1 Characteristics of the study population, Malaysia, April-June 2011

\begin{tabular}{|c|c|c|c|c|c|c|}
\hline \multirow[t]{2}{*}{ Socio-demographics } & \multicolumn{2}{|l|}{ Male } & \multicolumn{2}{|c|}{ Female } & \multicolumn{2}{|l|}{ All } \\
\hline & $n$ & $N(\%)$ & $n$ & $N(\%)$ & $n$ & $N(\%)$ \\
\hline & 8536 & 51.1 & 9695 & 48.9 & 18231 & 100 \\
\hline \multicolumn{7}{|l|}{ Locality } \\
\hline Urban & 4874 & 73.0 & 5730 & 73.3 & 10604 & 73.1 \\
\hline Rural & 3662 & 27.0 & 3965 & 26.7 & 7627 & 26.9 \\
\hline \multicolumn{7}{|l|}{ Age } \\
\hline $18-24$ & 1445 & 20.3 & 1448 & 20.1 & 2893 & 20.2 \\
\hline $25-34$ & 1889 & 26.7 & 2097 & 25.7 & 3986 & 26.2 \\
\hline $35-44$ & 1643 & 19.9 & 2000 & 20.2 & 3643 & 20.0 \\
\hline $45-54$ & 1620 & 16.4 & 1862 & 16.0 & 3482 & 16.2 \\
\hline $55-64$ & 1159 & 10.0 & 1301 & 10.2 & 2460 & 10.1 \\
\hline 65 and above & 780 & 6.7 & 987 & 7.8 & 1767 & 7.3 \\
\hline \multicolumn{7}{|l|}{ Ethnicity } \\
\hline Malay & 4858 & 48.5 & 5532 & 51.0 & 10390 & 49.8 \\
\hline Chinese & 1666 & 25.9 & 1856 & 25.0 & 3522 & 25.4 \\
\hline Indian & 651 & 6.8 & 808 & 7.3 & 1459 & 7.0 \\
\hline Others & 1361 & 18.8 & 1499 & 16.8 & 2860 & 17.8 \\
\hline \multicolumn{7}{|l|}{ Educational Level } \\
\hline Primary & 2106 & 22.1 & 2263 & 20.8 & 4369 & 21.4 \\
\hline Secondary & 4091 & 48.6 & 4191 & 45.6 & 8282 & 47.1 \\
\hline Tertiary & 1825 & 23.7 & 2040 & 23.9 & 3865 & 23.8 \\
\hline No formal education & 514 & 5.6 & 1201 & 9.7 & 1715 & 7.6 \\
\hline \multicolumn{7}{|l|}{ Household Income/month ${ }^{a}$} \\
\hline Less than RM2000 & 3102 & 32.3 & 4038 & 38.4 & 7140 & 35.3 \\
\hline RM2000-RM2999 & 1526 & 17.5 & 1562 & 16.1 & 3088 & 16.8 \\
\hline RM3000-RM3999 & 1172 & 14.0 & 1236 & 13.2 & 2408 & 13.6 \\
\hline At least RM4000 & 2736 & 36.2 & 2859 & 32.4 & 5595 & 34.3 \\
\hline \multicolumn{7}{|l|}{ Employment Status } \\
\hline Government/semi-government & 1075 & 12.3 & 1073 & 10.4 & 2148 & 11.4 \\
\hline Private & 3389 & 51.0 & 2308 & 33.9 & 5697 & 42.7 \\
\hline Self-employed & 2376 & 27.4 & 1243 & 13.2 & 3619 & 20.5 \\
\hline Homemaker/unpaid worker & 100 & 1.3 & 3094 & 33.9 & 3194 & 17.1 \\
\hline Retiree & 789 & 8.1 & 949 & 8.6 & 1738 & 8.3 \\
\hline \multicolumn{7}{|l|}{ Marital Status } \\
\hline Single & 2356 & 32.9 & 1875 & 24.0 & 4231 & 28.6 \\
\hline Married & 5954 & 65.2 & 6554 & 65.6 & 12508 & 65.4 \\
\hline Widow/Widower/Divorcee & 216 & 1.9 & 1254 & 10.4 & 1470 & 6.0 \\
\hline \multicolumn{7}{|l|}{ BMI Status } \\
\hline Underweight & 638 & 8.4 & 639 & 8.2 & 1277 & 8.3 \\
\hline Normal & 3833 & 48.0 & 3797 & 46.4 & 7630 & 47.2 \\
\hline Overweight & 2538 & 30.9 & 2615 & 27.8 & 5153 & 29.4 \\
\hline Obese & 1021 & 12.7 & 1729 & 17.6 & 2750 & 15.1 \\
\hline \multicolumn{7}{|l|}{ Smoking Status } \\
\hline Current smoker & 3973 & 46.9 & 160 & 1.9 & 4133 & 25 \\
\hline
\end{tabular}


Table 1 Characteristics of the study population, Malaysia, April-June 2011 (Continued)

\begin{tabular}{|c|c|c|c|c|c|c|}
\hline Non-current smoker & 4510 & 53.1 & 9430 & 98.1 & 13940 & 75 \\
\hline \multicolumn{7}{|l|}{ Physical Activity Level } \\
\hline Low & 2581 & 30.1 & 3899 & 40.4 & 6480 & 35.2 \\
\hline Moderate & 2729 & 32.5 & 3898 & 41.2 & 6627 & 36.7 \\
\hline High & 3122 & 37.4 & 1841 & 18.4 & 4963 & 28.1 \\
\hline \multicolumn{7}{|l|}{ Hypertension } \\
\hline Yes & 3130 & 33.7 & 3570 & 31.6 & 6700 & 32.7 \\
\hline No & 5330 & 66.3 & 6068 & 68.4 & 11398 & 67.3 \\
\hline \multicolumn{7}{|l|}{ Diabetes } \\
\hline Yes & 1555 & 15.8 & 1647 & 14.5 & 3202 & 15.2 \\
\hline No & 6754 & 84.2 & 7826 & 85.5 & 14580 & 84.8 \\
\hline
\end{tabular}

Abbreviations: RM Ringgit Malaysia

${ }^{\mathrm{a}} 1 \mathrm{RM} \approx 0.24$ US Dollar

of the respondents attained a tertiary level of education (college/university graduates). Men accrued a higher level of high-intensity PA whilst women were engaged more in low- and moderate-intensity activities. Almost 1 in every 3 adults was overweight or hypertensive and 2 in every 13 were diabetic.

Generally, both simple and multivariable linear regression (MLR) analyses demonstrated that PA level was positively associated with systolic blood pressure (SBP) $(P<0.05)$. However, such association was not significant between PA level and diastolic blood pressure (SDP) in the adjusted MLR analyses (Table 2). In contrast, both simple and multivariable linear regression (MLR) analyses revealed that there was a significant dose response relationship between PA level and blood glucose level $(P<0.05)$. Respondents with low level of PA had significantly higher blood glucose level as compared to those who were moderately or highly active (reference group), and also, those who were moderately active had significantly higher blood glucose level than their highly active counterparts (Table 3 ).

\section{Discussion}

This is the first national, multi-ethnic study to crosssectionally examine the effects of PA against SBP, DBP and blood glucose among Malaysians aged 18 years and above, while controlling for other potential confounders. The present findings demonstrated a positive association between physical activity and systolic blood pressure. However, observations from several well-controlled cohort studies $[8,9]$ and randomised control trials (RCTs) $[10,11]$ had proven unequivocally an independent, negative association between PA and blood pressure.

One of the plausible explanations for the above findings could be due to differential misclassification, in which either the hypertensive respondents were differentially misclassified as having high PA or those with low PA were differentially misclassified as non-hypertensive. However, the latter (misclassification of hypertensive status) was unlikely as blood pressure of respondents were measured twice at a 10-min interval using calibrated devices, OMRON HEM-907 by trained nurses. Therefore differential misclassification of hypertensive respondents

Table 2 Coefficients from multiple linear logistic regression of systolic and diastolic blood pressure on physical activity level

\begin{tabular}{|c|c|c|c|c|c|c|c|c|c|c|c|c|}
\hline \multirow{3}{*}{$\begin{array}{l}\text { Physical } \\
\text { activity level }\end{array}$} & \multicolumn{6}{|c|}{ Systolic blood pressure } & \multicolumn{6}{|c|}{ Diastolic blood pressure } \\
\hline & \multicolumn{3}{|l|}{ Crude } & \multicolumn{3}{|l|}{ Adjusted } & \multicolumn{3}{|l|}{ Crude } & \multicolumn{3}{|l|}{ Adjusted } \\
\hline & Coefficient & $\begin{array}{l}\text { Standard } \\
\text { error }\end{array}$ & ${ }^{*} p$-value & Coefficient & $\begin{array}{l}\text { Standard } \\
\text { error }\end{array}$ & ${ }^{*} p$-value & Coefficient & $\begin{array}{l}\text { Standard } \\
\text { error }\end{array}$ & ${ }^{*} p$-value & Coefficient & $\begin{array}{l}\text { Standard } \\
\text { error }\end{array}$ & $\overline{p \text {-value }}$ \\
\hline Low (high) & -2.30 & 0.54 & $<0.001$ & -1.35 & 0.49 & 0.02 & -1.20 & 0.33 & 0.001 & -0.49 & 0.33 & 0.31 \\
\hline Moderate (high) & -1.72 & 0.51 & & -0.57 & 0.48 & & -0.41 & 0.32 & & -0.24 & 0.32 & \\
\hline$n$ & 17,568 & & & 14,923 & & & 17,567 & & & 14,922 & & \\
\hline
\end{tabular}

${ }^{a}$ Coefficient values were adjusted for gender, locality, age, ethnicity, educational level, household monthly income, employment and marital status, body mass index status and smoking status

*Significant $p$ values at $95 \%$ confidence interval 
Table 3 Coefficients from multiple linear logistic regression of blood glucose on physical activity level

\begin{tabular}{|c|c|c|c|c|c|c|}
\hline \multirow{2}{*}{$\begin{array}{l}\text { Physical activity } \\
\text { level }\end{array}$} & \multicolumn{3}{|l|}{ Crude } & \multicolumn{3}{|l|}{ Adjusted } \\
\hline & $\overline{\text { Coefficient }}$ & Standard error & ${ }^{*} p$-value & $\overline{\text { Coefficient }^{a}}$ & Standard error & ${ }^{*} p$-value \\
\hline Low (High) & 0.26 & 0.07 & 0.002 & 0.17 & 0.07 & 0.04 \\
\hline Moderate (High) & 0.12 & 0.06 & & 0.03 & 0.06 & \\
\hline $\mathrm{n}$ & 16,181 & & & 13,973 & & \\
\hline
\end{tabular}

${ }^{a}$ Coefficient values were adjusted for gender, locality, age, ethnicity, educational level, household monthly income, employment and marital status, body mass index status and smoking status

*Significant $p$ values at $95 \%$ confidence interval

as highly active, or normal respondents as lowly active could occurred as a result of information bias as the use of IPAQ in the estimation of PA level was rather subjective and subjected to recall bias and tendency of respondents to report a socially desirable response, which may lead to an over-estimation of PA. Lee and his colleagues who performed a systematic review on the validation of IPAQ-SF with objective measurements stated that IPAQ-SF typically overestimated physical activity by an average of $84 \%$ [21]. Therefore, the possible presence of differential misclassification of PA due to poor PA ascertainment in attenuating the real effect of PA against blood pressure should not be overlooked. In addition, more than three-quarters of respondents with known hypertension claimed that they were on oral anti-hypertensive drugs within the past 2 weeks of the interview date (data not shown), and this may again attenuate the beneficial effect of PA against SBP. Furthermore, the cross-sectional nature of the present study had also limited the inference of a direct causal relationship between PA and blood pressure. Therefore, only a properly conducted prospective cohort on healthy individuals [22] or a RCT which employs objective measurement for PA, such as accelerometer, pedometer or doubly labelled water [21], could conclusively determine the causal as well as dose-response relationship between PA level and blood pressure.

In contrast, a significant negative association was observed between PA and blood glucose among Malaysian adults. The present findings were consistent with those reported from other cross-sectional studies $[6,7,12]$ and were corroborated by prospective observational studies $[8,23]$. Furthermore, an interventional study by Knowler et al. [24] had demonstrated a $58 \%$ (96\% CI: 48-66) reduction of diabetes incidence among the intervention group, which targeted at least a $7 \%$ weight loss and at least $150 \mathrm{~min}$ of PA per week, compared to placebo. Additionally, findings from a large cohort study among more than 70,000 healthy women aged 40-65 years in the United States had substantiated the beneficial effects of moderate- and vigorous-intensity PA against diabetes, whereby brisk walking and more vigorous exercise were found to be associated with a $25 \%$ reduction in diabetes incidence [25].
Despite the cross-sectional nature of the study and the use of a subjective instrument (IPAQ) in the estimation of PA level, the large sample size and its representativeness as well as the high response rate were the major strengths of the present study. In addition, underestimations of the prevalence of hypertension and diabetes among the population were unlikely as measurements of blood pressure and fasting blood glucose levels were taken properly by trained nurses using calibrated devices rather than self-reported.

\section{Conclusions}

Generally, a significant dose-response relationship was observed between physical activity and blood glucose, but not between physical activity and blood pressure. Nonetheless, in order to elucidate the true association between physical activity and hypertension or diabetes, the use of an objective instrument for the estimation of the physical activity level is highly recommended for future study.

\section{Abbreviations}

AAMI: American Association for the Advancement Medical Instrumentation; BHS: British Hypertension Society; BMI: body mass index; BOD: burden of disease; Cl: confidence interval; CVD: cardiovascular disease; DALYs: disabilityadjusted life years; DBP: diastolic blood pressure; DOS: Department of Statistics; EB: enumeration block; FVs: fruits and vegetables; IPAQ: international physical activity questionnaire; LQ: living quarter; MET: metabolic equivalent; MLR: multivariable linear regression; MREC: Medical Review and Ethics Committee; NHMS: National Health and Morbidity Survey; PA: physical activity; PSU: primary sampling unit; RCT: randomised controlled trial; SBP: systolic blood pressure; SD: standard deviation; SSU: secondary sampling unit; WHO: World Health Organisation; YLLs: years of life lost.

\section{Competing interests}

The authors declare that they no competing interests.

\section{Authors' contributions}

TCH as the first author, collected data and supervised data collection at the field, analyzed and interpreted the data, and drafted the manuscript. CYY and LKH helped in literature review, prepared the Results and Discussion sections of the article and critically reviewed the manuscript. LKK collected data, supervised data collection at the field and revised the manuscript critically. KCC and YPS helped in data analysis and interpretation and helped to draft the manuscript. AO and FY designed the study and helped in data analysis. LHL and NWA reviewed and revised the manuscript for important intellectual content. TA gave substantial contribution to the conception and design of the study, and critically reviewed the manuscript. All authors had given the final approval to publish the submitted manuscript in its present form. 


\section{Acknowledgements}

The authors would like to thank the Director General of Health, Malaysia for his permission to publish this study. We would like to also convey our sincerest tribute to the field supervisors, nurses and data collectors for their dedicated efforts in conducting this survey. This research was supported by the Research and Development Fund, Ministry of Health Malaysia (NMRR-10-757-6837).

\section{Author details}

${ }^{1}$ Institute for Medical Research, Ministry of Health Malaysia, Jalan Pahang, Kuala Lumpur 50588, Malaysia. ${ }^{2}$ Institute for Public Health, Ministry of Health Malaysia, Jalan Bangsar, Kuala Lumpur 50590, Malaysia.

Received: 17 September 2014 Accepted: 18 November 2015 Published online: 03 December 2015

\section{References}

1. World Health Organization. Global health risks: mortality and burden of disease attributable to selected major risks. Geneva: World Health Organization; 2009. ISBN 978-924-1563-87-1.

2. $\quad \mathrm{PH}$ (Institute for Public Health). The third national health and morbidity survey (NHMS III). Kuala Lumpur: Ministry of Health Malaysia; 2006. ISBN 978-983-3887-08-8

3. $\mathrm{IPH}$ (Institute for Public Health). The forth national health and morbidity survey (NHMS IV). Kuala Lumpur: Ministry of Health Malaysia; 2011. ISBN 978-967-3887-68-2.

4. $\quad \mathrm{PH}$ (Institute for Public Health). The second Malaysian burden of disease and injury study. Kuala Lumpur: Ministry of Health Malaysia; 2012. ISBN 978983-2387-06-0.

5. Ansari RM. Effect of PA and obesity on type 2 diabetes in a middle-aged population. J Env Public Health. in press.

6. Sobngwi E, Mbanya J-CN, Unwin NC, Kengne AP, Fezeu L, Minkoulou EM, et al. PA and its relationship with obesity, hypertension and diabetes in urban and rural Cameroon. Int J Obesity. 2002:26:1009-16.

7. Sullivan PW, Morrato EH, Ghushchyan V, Wyatt HR, Hill JO. Obesity, inactivity, and the prevalence of diabetes and diabetes-related cardiovascular comorbidities in the U.S., 2000-2002. Diabetes Care. 2005;28(7):1599-603.

8. Hu G, Barengo NC, Tuomilehto J, Lakka TA, Nissinen A, Jousilahti P. Relationship of PA and body mass index to the risk of hypertension: a prospective study in Finland. Hypertension. 2004:43:25-30.

9. Paffenbarger Jr RS, Wing AL, Hyde RT, Jung DL. PA and incidence of hypertension in college alumni. Am J Epidemiol. 1983;117:245-57.

10. Whelton SP, Chin A, Xin X, He J. Effect of aerobic exercise on blood pressure: a meta-analysis of randomized, controlled trials. Ann Intern Med. 2002;136:493-503.

11. Kelley GA, Kelley KS. Progressive resistance exercise and resting blood pressure: a meta-analysis of randomized controlled trials. Hypertension 2000;35:838-43.

12. Sakuta $H$, Suzuki T. PA and selected cardiovascular risk factors in middle-aged male personnel of self-defense forces. Jap J Ind Health. 2005:44:184-9.

13. Williamson DF, Vinicor F, Bowman BA. Primary prevention of type 2 diabetes mellitus by lifestyle intervention: implications for health policy. Ann Intern Med. 2004;140(11):951-7.

14. Fadhli Y, Azahadi O, Noor Ani A, Balkish MN, Ahmad Jessree K, Tahir A. Approaches in methodology of a population-based study in Malaysia: the national health and morbidity survey 2011 (NHMS 2011). Mal J Med Health Sci. 2013;9(2):25-33.

15. IPAQ Research Committee. International physical activity questionnaire. [https://sites.google.com/site/theipaq/scoring-protocol]

16. Gurpreet $\mathrm{K}$, Tee GH, Karuthan C. Evaluation of the accuracy of the Omron HEM-907 blood pressure device. Med J Malaysia. 2008;63(3):239-43.

17. Joint National Committee 7. Complete report: seventh report of the Joint National Committee on prevention, detection, evaluation and treatment of high blood pressure. Hypertension. 2003;42:1206-652.

18. Noor Ani A, Ummi Nadiah Y, Noor Azah D, Hamizatul Akmal AH, Tahir A Sensitivity and specificity of CardioChek ${ }^{\oplus} \mathrm{PA}$ in detecting individuals with abnormal cholesterol and glucose level. Int J Biomed. 2012;2(2):132.135.

19. Ministry of Health Malaysia. Clinical practice guidelines: management for type 2 diabetes mellitus. 4th ed. Kuala Lumpur: Ministry of Health Malaysia; 2009.
20. World Health Organization. Global database on BMl index. [http://apps.who. int/bmi/index.jsp?introPage=intro_3.html]

21. Lee PH, Macfarlane DJ, Lam TH, Stewart SM. Validity of the International Physical Activity Questionnaire short form (IPAQ-SF): a systematic review. Int J Behav Nutr Phys Act. 2011;8:115.

22. Shiroma EJ, Lee I. Physical activity and cardiovascular health: lessons learned from epidemiological studies across age, gender, and race/ethnicity. Circ 2010;122:743-52

23. Weinstein AR, Sesso HD, Lee IM, Cook NR, Manson JE, Buring JE, et al. Relationship of PA vs body mass index with type 2 diabetes in women. JAMA. 2004:292:1188-94.

24. Knowler WC, Barrett-Connor E, Fowler SE, Hamman RF, Lachin JM, Walker $E A$, et al. Reduction in the incidence of type 2 diabetes with lifestyle intervention for metformin. N Engl J Med. 2002;346(6):393-403.

25. Hu FB, Sigal RJ, Rich-Edwards JW, Colditz GA, Solomon CG, Willet WC, et al. Walking compared with vigorous PA and risk of type 2 diabetes in women: a prospective study. JAMA. 1999;282:1433-9.

\section{Submit your next manuscript to BioMed Central and we will help you at every step:}

- We accept pre-submission inquiries

- Our selector tool helps you to find the most relevant journal

- We provide round the clock customer support

- Convenient online submission

- Thorough peer review

- Inclusion in PubMed and all major indexing services

- Maximum visibility for your research

Submit your manuscript at www biomedcentral com/submit 